\title{
Functional and cellular characterization of human Retinoic Acid Induced 1 (RAl1) mutations associated with Smith-Magenis Syndrome
}

\author{
Paulina Carmona-Mora ${ }^{1,2 \dagger}$, Carolina A Encina ${ }^{2,3 \dagger}$, Cesar P Canales ${ }^{1,2}$, Lei Cao ${ }^{1}$, Jessica Molina ${ }^{2}$, Pamela Kairath ${ }^{2,3}$,
} Juan I Young ${ }^{1,2,4}$, Katherina Walz ${ }^{1,2^{*}}$

\begin{abstract}
Background: Smith-Magenis Syndrome is a contiguous gene syndrome in which the dosage sensitive gene has been identified: the Retinoic Acid Induced 1 (RA/1). Little is known about the function of human RAl1.

Results: We generated the full-length CDNA of the wild type protein and five mutated forms: RAl7-HA 2687delC, RAl1-HA 3103delC, RAl1 R960X, RAl1-HA Q1562R, and RAl1-HA S1808N. Four of them have been previously associated with SMS clinical phenotype. Molecular weight, subcellular localization and transcription factor activity of the wild type and mutant forms were studied by western blot, immunofluorescence and luciferase assays respectively. The wild type protein and the two missense mutations presented a higher molecular weight than expected, localized to the nucleus and activated transcription of a reporter gene. The frameshift mutations generated a truncated polypeptide with transcription factor activity but abnormal subcellular localization, and the same was true for the 1-960aa N-terminal half of RAl1. Two different C-terminal halves of the RAl1 protein (1038aaend and 1229aa-end) were able to localize into the nucleus but had no transactivation activity.

Conclusion: Our results indicate that transcription factor activity and subcellular localization signals reside in two separate domains of the protein and both are essential for the correct functionality of RAl1. The pathogenic outcome of some of the mutated forms can be explained by the dissociation of these two domains.
\end{abstract}

\section{Background}

A large fraction of genome variation between individuals is comprised of submicroscopic copy number variation of DNA segments (CNVs) [1-6]. Genomic disorders are the clinical manifestation of pathological CNV. They are frequent conditions ( $\sim 1$ per 1,000 births) and often sporadic resulting from de novo rearrangements [7]. In a subset of such conditions the rearrangements comprise multiple unrelated contiguous genes that are physically linked and thus have been referred to as contiguous gene syndromes (CGS). An increasing number of CGS are being described, each of them presenting a complex and specific phenotype. Although several genes are usually present in the segmental aneuploidy; only a

\footnotetext{
* Correspondence: kwalz@med.miami.edu

+ Contributed equally

'John P. Hussman Institute for Human Genomics, Miller School of Medicine, University of Miami, Miami, Florida, USA

Full list of author information is available at the end of the article
}

small subset of them conveys phenotypes as a function of copy number alteration. These particular genes are referred to as "dosage sensitive genes".

The Smith-Magenis Syndrome, SMS, (OMIM\# 182290) is a CGS associated with a microdeletion within chromosome 17 band p11.2. SMS was first described in 1986 with a birth prevalence estimated at $1 / 25,000$. The clinical phenotype includes craniofacial abnormalities, brachydactyly, self injurious behavior, sleep abnormalities and mental retardation. Less commonly reported is cleft palate, congenital heart defects, seizures, hearing impairment and urinary tract anomalies [8]. Molecular studies revealed a common deleted region of $\sim 4 \mathrm{Mb}$ in the majority of SMS patients $(>70-80 \%)$ [9-11]. Unusual sized deletions (smaller or larger) were observed in $20-25 \%$ of patients [12-14]. By examining the breakpoints in unusual sized deletions, the SMS critical region was redefined to a $\sim 950 \mathrm{~kb}$ interval, in which 15 genes and eight predicted genes were present [11-14]. 
Retinoic Acid Induced 1 gene (RAI1) is located in the middle of the SMS critical region. Point mutations (nonsense and frameshift as well as missense alleles) in RAI1 were identified in patients with clinical presentation of SMS but no molecular deletion found by FISH [15-18], suggesting that RAI1 is the dosage sensitive gene causative of SMS. Studies on mouse models [19] and humans $[20,21]$ indicate that $R A I 1$ is likely the dosage sensitive gene responsible for clinical features in the PotockiLupski Syndrome (PTLS), (OMIM\# 610883) a neurobehavioral disorder with autistic features that is caused by reciprocal duplication of the $17 \mathrm{p} 11.2$ region [20-23]. The RAI1 gene consists of six exons [24] that span over $120 \mathrm{~kb}$. The third exon contains $>90 \%$ of the coding region and it is within this exon where all mutations have been identified to date.

Little is known about the cellular and developmental role of RAI1. Expression of GT1, a splice variant of Rai1 was markedly up-regulated by treatment with retinoic acid in a mouse carcinoma cell line P19 [25]. A polymorphic CAG repeat is present in the $\mathrm{N}$-terminus of the RAI1 protein, the length of which is associated with the age of onset of spinocerebellar ataxia type 2 [26] and the response to neuroleptic medication in schizophrenia [27]. Moreover, RAI1 was recently associated with non syndromic autism [28]. Bioinformatic analyses have suggested that RAI1 might be a transcriptional regulator $[15,16]$. RAI1 contains several patches of $50 \%$ similarity with TCF20, a transcriptional cofactor, and these two genes have a similar gene structure. RAI1, in both human and mouse, have two putative bipartite nuclear localization signals (NLSs) predicted in silico, and possesses a zinc finger like plant homeo domain (PHD) in the C-terminus, which is also present in the trithorax family of chromatin remodeling transcriptional regulators [16]. In vitro studies of the murine Rai1 protein indicated that it can be transported to the nucleus and has transactivation activity [29]. However, no systematic analysis of the human RAI1 protein has been done. Here we describe the characterization of the wild type RAI1 protein, plus five mutated forms of the protein, including four that have been associated with the SMS clinical phenotype. Subcellular localization of the resulting proteins and transcription factor activity were studied for the wild type and mutant forms. Our results indicate that the transcription factor activity and subcellular localization of the protein are essential for the pathogenic outcome of some of the mutated forms.

\section{Results}

The transcription factor activity of the murine Rai1 protein is dependent on the cell type

Human and mouse RAI1 share more than $80 \%$ in DNA and amino acid homology sequence. Moreover, several mouse models for SMS were developed and studied, and they presented similar phenotypes to those found in the SMS patients, reinforcing the idea of a comparable function for murine and human RAI1 [30]. A previous report by Bi et al., [29] showed that the murine Rai1 protein presented a mild transcription factor activity and a nuclear subcellular localization. In order to corroborate previous findings and to set up the optimal conditions for our studies of human RAI1, we subcloned the murine Rai1 full-length cDNA kindly donated by Dr. James Lupski, into different vectors that allowed us to see the molecular weight, subcelullar localization and transcription factor activity of the murine protein (figure 1). The expected $201.5 \mathrm{kDa}$ molecular weight for the murine protein was similar to the obtained molecular weight (213 kDa) (figure $1 \mathrm{~B})$, as well as the nuclear subcellular localization (figure 1C). It was previously reported that Rai1 has relatively weak transactivation activity in transfected HeLa cells in comparison to other transcription factors [29]. Neurobehavioral abnormalities are the prevalent clinical presentation in SMS patients. Based on this we wanted to examine whether Rai1 has a different transactivation activity in cells derived from murine neuroblastoma, the Neuro-2a cell line. In order to do this, full-length Rai1 was fused with the GAL4 DNA binding domain (GAL4-BD) and co-transfected into HeLa and Neuro-2a cells with a luciferase reporter plasmid which contains five tandem repeats of yeast GAL4-binding sites upstream of the luciferase gene, plus a plasmid containing the beta galactosidase gene to control transfection efficiency. The results showed that the transcription factor activity in HeLa cells is $2.2+/-1.5$ folds over the empty vector and in Neuro-2a cells is $61.3+/-11.2$ indicating that the murine protein has a transactivational activity several times stronger in the Neuro-2a cell line than in HeLa cells, suggesting that there is a specific machinery in neuronal cells that may be related to Rai1 transcription factor activity (figure 1D).

\section{Human RAl1 is a nuclear protein with transcription factor activity}

In a first attempt to understand and characterize the function of human RAI1 we generated the full-length cDNA coding for the wild type protein. The full-length cDNA was obtained as described in Material and Methods. The final full-length sequence is the same as the one reported in NM_030665 with SNP A/G at position 1992. In order to have an easy way to identify the transfected RAI1 from the endogenous protein, an HA tag was added in the 3' end (figure 1A). Since we found that Rai1 activity was dependent of cellular type, we performed all our studies in mouse Neuro-2a neuroblastoma cells. Neuro-2a cell line was preferred over the SH-SY5Y 


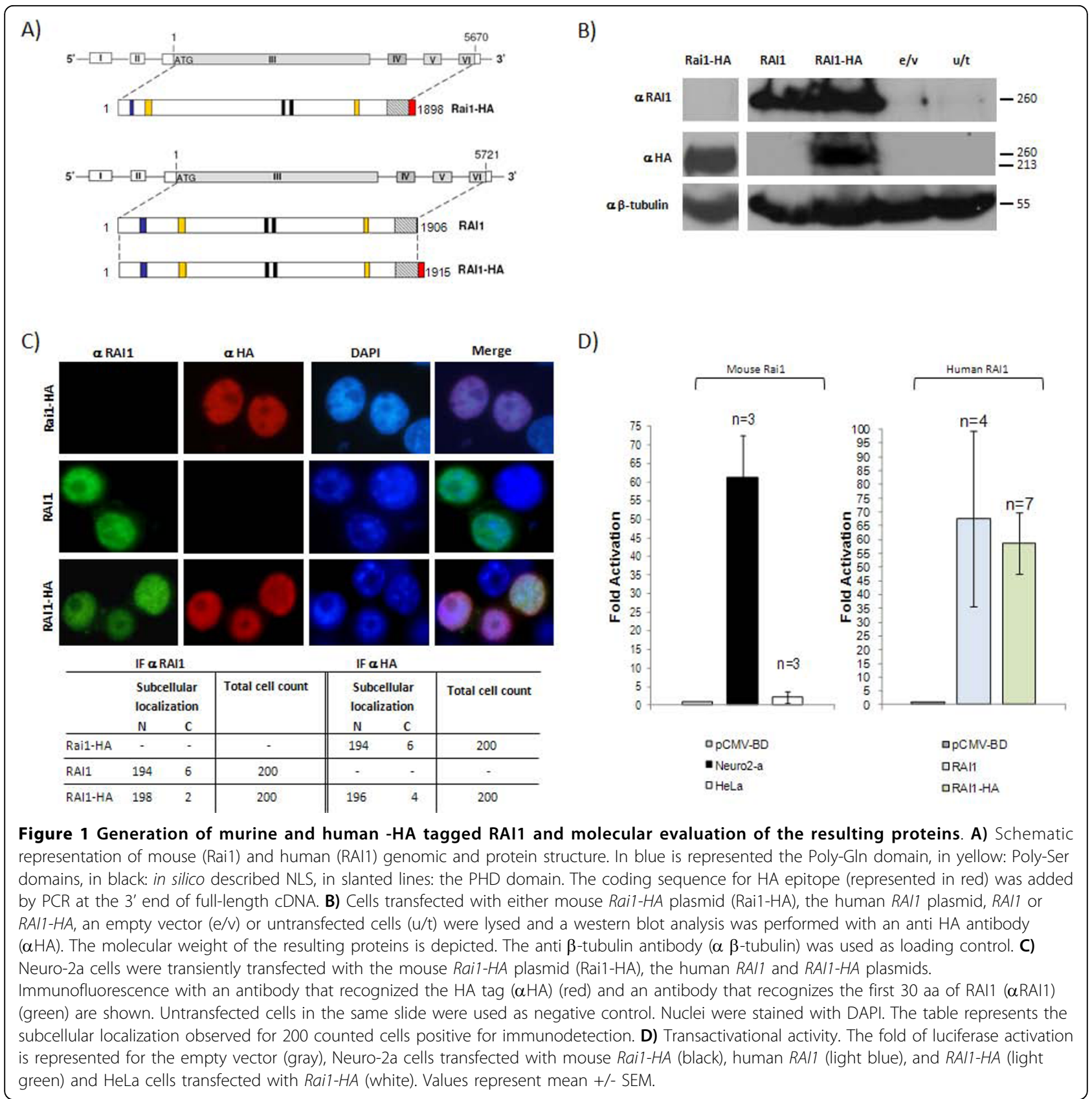

(human neuroblastoma) cell line despite its murine origin, since the human ones grow at an extremely slow rate and making them very difficult to transfect. In order to determine the molecular weight of the protein, both clones the RAI1 and RAI1-HA cDNA were transiently transfected, and $48 \mathrm{~h}$ post-transfection the cell lysate was run in a $10 \%$ SDS-PAGE gel. The predicted in silico molecular weight for RAI1 is $203 \mathrm{kDa}$. As can be observed in figure $1 \mathrm{~B}$, the molecular weight of both proteins is $\sim 260 \mathrm{kDa}$, and the addition of the HA tag is not inducing instability of the resulting protein. The difference between the molecular weight predicted and the obtained could be explained by post-translational modifications (PTM) for example glycosylations. We found several predicted glycosylation sites on the first amino-terminal half of RAI1 (analysis in NetOGlyc 3.1 server, EXPASY Tools, http://www.expasy.org) [31].

To prove if the human protein has transcription factor activity, we subcloned the RAI1 and RAI1-HA full-length cDNA into a GAL4-binding domain vector (pCMV-BD, Stratagene). It is important to note that the presence of the GAL4-binding domain is enough to localize the 
protein to the nucleus [32]. Transfection of each clone plus the reporter gene was carried out and $48 \mathrm{~h}$ posttransfection the cells were lysed and the activity of the luciferase reporter gene was measured. As can be seen in figure 1D, the expression of the wild type RAI1 and RAI1HA derives in an $67.5+/-31.8$ and $58.8+/-11.1$ fold increase of the luciferase activity respectively, indicating that the human protein presented transcription factor activity and that the addition of the HA tag did not interfere with the activity of the resulting protein. RAI1 has a bipartite nuclear localization signal predicted by informatics analysis [15]. Nuclear subcellular localization was found for both, the RAI1 and RAI-HA proteins (figure 1C) at $36 \mathrm{~h}$ post-transfection and this result was confirmed with two different antibodies, one that recognized an epitope within the first 30 amino acids in the $\mathrm{N}$-terminus portion of the RAI1 protein and the anti HA antibody, which recognized the C-terminus end in the RAI1-HA clone. These results indicate that the human RAI1 protein, with or without the HA tag, has a nuclear localization and the ability to activate the transcription of a reporter gene.

\section{The N-terminal truncated RAI1 polypeptides retain the} transcription factor activity but localize in the cytoplasm Most Smith-Magenis cases present a deletion in chromosome 17p11.2 that causes the haploinsufficiency of the RAI1 gene. However, in some patients heterozygous mutations have been found within the RAII coding region. In order to study how these mutations can be detrimental we analyzed two independent deletions of one $\mathrm{C}$ within the coding region, the RAI1 2687delC (not found yet in any patient and spontaneously originated in our laboratory) and the RAI1 3103delC [18] (figure 2A). Theoretically in both cases the deletion of a $\mathrm{C}$ within the $C$ tract will result in a frameshift, misincorporation of amino acids and a subsequent premature stop codon. In the case of RAI1-HA 2687delC a misincorporation of 53 amino acids followed by a stop codon is expected, while in the RAI1-HA 3103delC protein the misincorporation will be 28 amino acids. In order to avoid the possible interference of the misincorporated amino acids in the following studies we also generated the RAI1 R960X mutation [18], where an arginine is replaced by a stop codon in the coding sequence generating a truncated protein, with no addition of extra amino acids. In order to determine the molecular weight of the resulting proteins, the three clones were transiently transfected, and $48 \mathrm{~h}$ post-transfection the cell lysate was run in a 10\% SDS-PAGE gel. The predicted molecular weights for the proteins originated by RAI1-HA 2687delC, RAI1$H A$ 3103delC and RAI1 R960X are 102, 114 and 103 $\mathrm{kDa}$ respectively. As can be observed in figure $2 \mathrm{~B}$, the obtained molecular weight of the three truncated proteins was $\sim 150,170$ and $136 \mathrm{kDa}$ respectively. These differences coincide with the predicted versus observed molecular weight differences found for the wild type protein with or without the HA tag, suggesting that the alleged modifications reside in the $\mathrm{N}$-terminal half of RAI1.

We evaluated the transcription factor activity for the truncated products by subcloning the three mutant forms cDNA into the $\mathrm{pCMV-BD}$ vector and posterior transfection of each clone plus the reporter gene into Neuro-2a cells. Forty eight hours post-transfection the cells were lysed and the activity of the luciferase reporter gene was measured. As can be seen in figure $2 \mathrm{C}$, all truncated proteins gave an increment of $233.2+/-19.2$ (for RAI1 2687delC), $179.1+/-24.1$ (for RAI1 3103delC), and 282.5 +/- 23.8 (for RAI1 R960X), in percentage of activation in comparison with the $100 \%$ of the wild type, indicating that the truncated polypeptides retained the transcription factor activity. All the truncated proteins showed a significant increased percentage of transcription activation when compared to the wild type protein $(\mathrm{P}$ value $\leq 0.01)$. The following step was to evaluate the subcellular localization of the truncated fragments in the absence of the GAL4-binding domain since the presence of this domain is enough to localize any protein to the nucleus [32]. The resulting truncated polypeptides would not include the hypothetical Nuclear Localization Signals (NLSs). Cytoplasmatic subcellular localization was found for all the

RAI1-HA 2687delC, RAI1-HA 3103delC and RAI1 R960X polypeptides (figure 2D). All together these results indicate that RAI1-HA 2687delC, RAI1-HA 3103delC and RAI1 R960X are generating truncated polypeptides that retain the transcription factor activity. However, they are not localized in the nucleus but in the cytoplasm of cells.

\section{Nuclear localization signals are situated in the C-terminus of the human RAI1 protein}

In order to verify that the C-terminal portion of the RAI1 protein is the one retaining the nuclear localization signals we generated two different fragments, one beginning at Met 1038 and the other beginning at Met 1229 of the RAI1 protein. The difference between them contains the sequence that was assigned as the bipartite NLS by in silico methods [15]. Both C-terminal halves were generated as described in Material and Methods (figure 3A). In order to determine the molecular weight of the resulting proteins, both clones were transiently transfected, and $48 \mathrm{~h}$ post-transfection the cell lysate was run in a $10 \%$ SDS-PAGE gel. As can be observed in figure $3 \mathrm{~B}$, the molecular weight of both truncated proteins was $\sim 115 \mathrm{kDa}$ and $85 \mathrm{kDa}$ respectively as predicted; and interestingly these results differ from those obtained with the other proteins analyzed further 

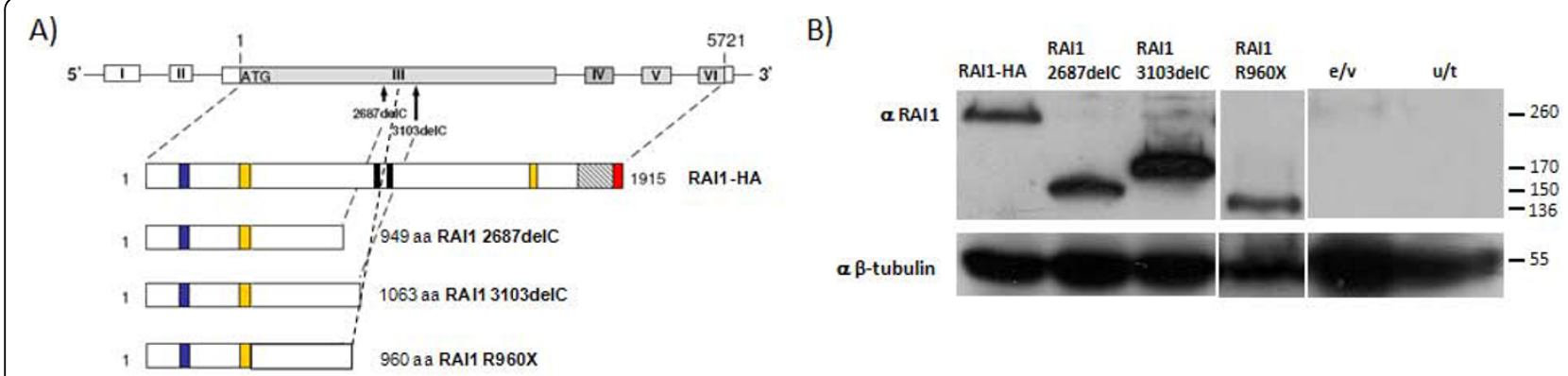

C)

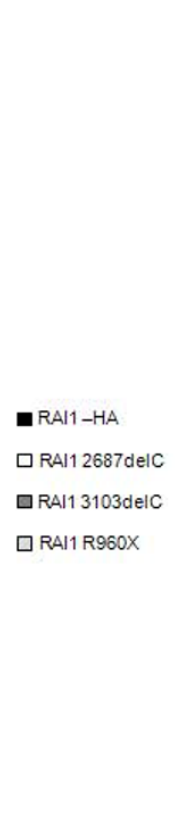

D)

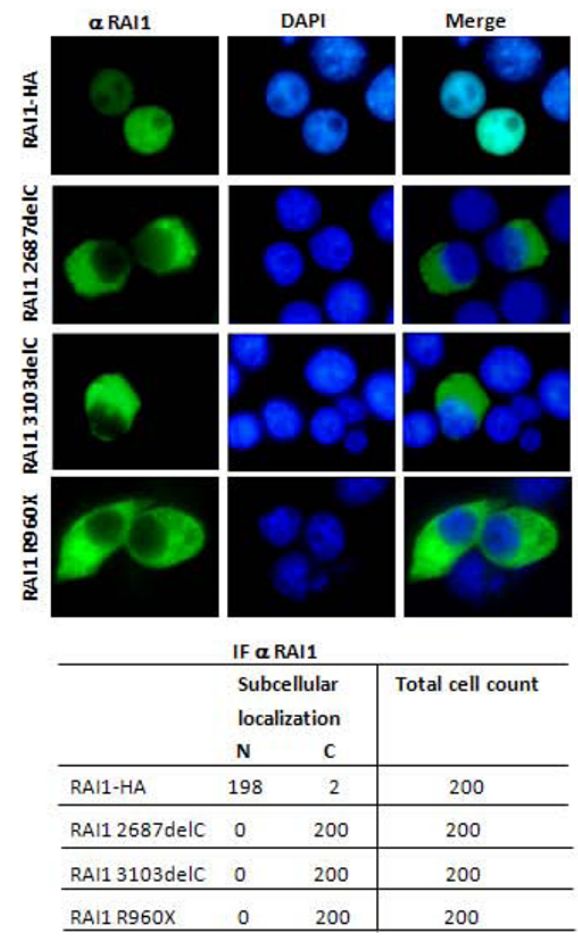

Figure 2 Evaluation of truncated proteins. A) Schematic representation of the two truncated RAl1 proteins generated by the deletion of a C in positions 2687 and 3103, plus RAl1 R960X. In blue is represented the Poly-Gln domain, in yellow: Poly-Ser domains, in black: in silico described NLS, in slanted lines: the PHD domain. The coding sequence for HA epitope is represented in red. B) Molecular weight for all truncated proteins was calculated by western blot analysis utilizing anti RAl1 antibody in transfected Neuro-2a cells. The molecular weight obtained for 2687 delC, 3103delC and R960X is indicated. e/v: cells transfected with empty vector; u/t: untransfected Neuro-2a cells. C) The percentages of activation for the proteins 2687delC (white), 3103delC (grey) and R960X (light grey) are represented. The wild type (black) is considered as 100\% of transcription activity. Values represent mean +/- SEM. (*: $P \leq 0.01$ ). D) Immunofluorescence was performed with anti RAl1 antibody (green). Nuclei were stained with DAPI. The table represents a summary of the subcellular localization found in 200 cells. $\alpha=$ antibody against RAl1.

supporting the possibility of a specific PTM in the Nterminal half of RAI1. We evaluated the transcription factor activity for the C-terminal halves of RAI1 by subcloning them into the $\mathrm{pCMV}-\mathrm{BD}$ vector with posterior transfection of each clone plus the reporter gene into Neuro-2a cells. As can be seen in figure 3C, both Cterminal halves of RAI1 were unable to activate the transcription of the luciferase reporter gene, since no luciferase activity could be measured in any of the assays. To evaluate the subcellular localization of the truncated fragments, both halves were transfected into Neuro-2a cells and the subcellular localization assayed with anti HA antibody. As can be observed, both halves were found in the nucleus suggesting the presence of extra NLS (figure 3D). Altogether these results indicate that the $\mathrm{N}$-terminal region of the human protein has the transcription factor activity and it is in the C-terminal half that the nuclear localization signaling resides.

\section{No alterations were found for RAI1 Q1562R and RAI1 S1808N mutants}

As we mentioned earlier, there are only rare cases with patients with Smith-Magenis Syndrome associated with heterozygous missense mutations in the RAII coding 


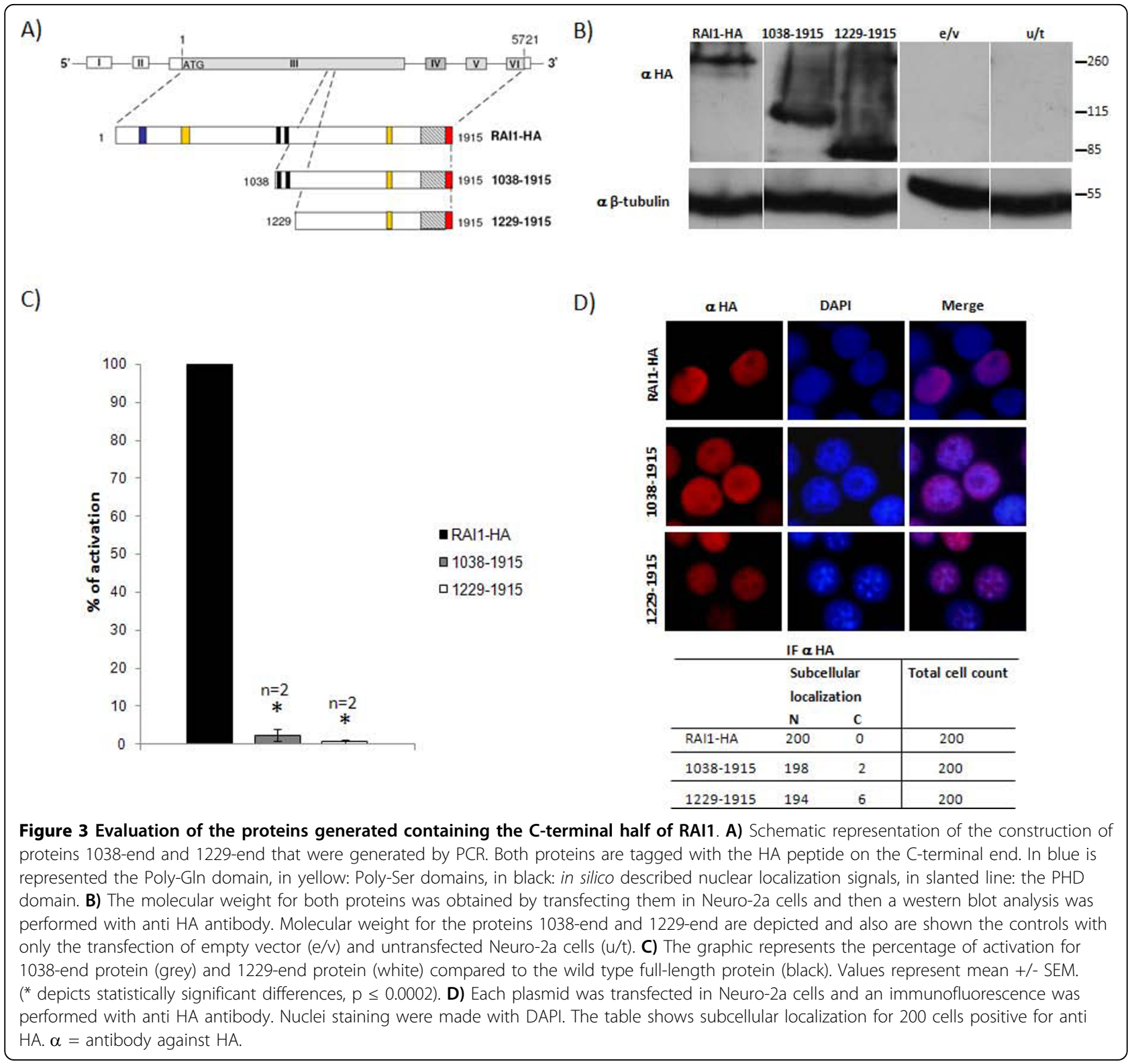

region. In two of these cases, a missense mutation was found: RAI1 Q1562R and RAI1 S1808N [17]. In order to investigate if these mutations were affecting the stability, subcellular localization or transcription activity function of the RAI1 protein we generated both mutations as described in Material and Methods (figure 4A). To determine the molecular weight of the resulting proteins, both clones were transiently transfected, and $48 \mathrm{~h}$ post-transfection the cell lysate was run in a $10 \%$ SDSPAGE gel. As can be observed in figure 4B, the molecular weight of both proteins is $\sim 260 \mathrm{kDa}$ similar to the wild type protein. Moreover, none of the mutations seem to give the protein any instability, since the relative signal for both mutants and the wild type RAI1 protein utilizing $\beta$-tubulin as loading control protein is the same for all of them. Although there could be differences between transfection efficiency of the samples, we have found by densitometric analysis of bands from different western blots $(\mathrm{n}=3)$, that the ratio RAI1/ $\beta$-tubulin is the same for wild type, RAI1-HA Q1562R and RAI1-HA S1808N ( $\sim$ in all cases) (data not shown).

For both mutants we evaluated the transcription factor activity, in the same way that was previously done for the other proteins. As can be seen in figure $4 \mathrm{C}$, both RAI1-HA Q1562R and RAI1-HA S1808N mutated proteins can give an increment of $120.5+/-20.4$ and $113.7+/-8.6$ percentage of activation of luciferase 


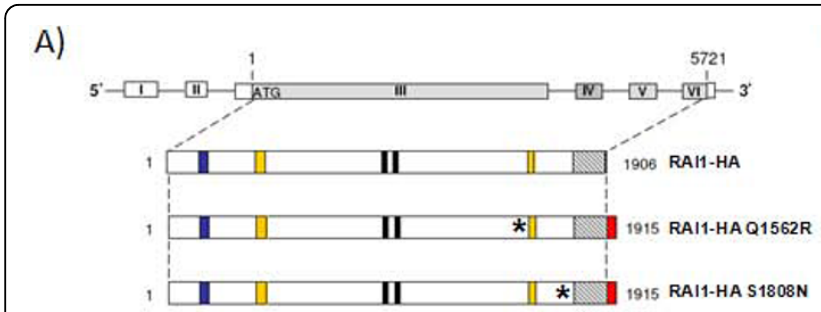

C)

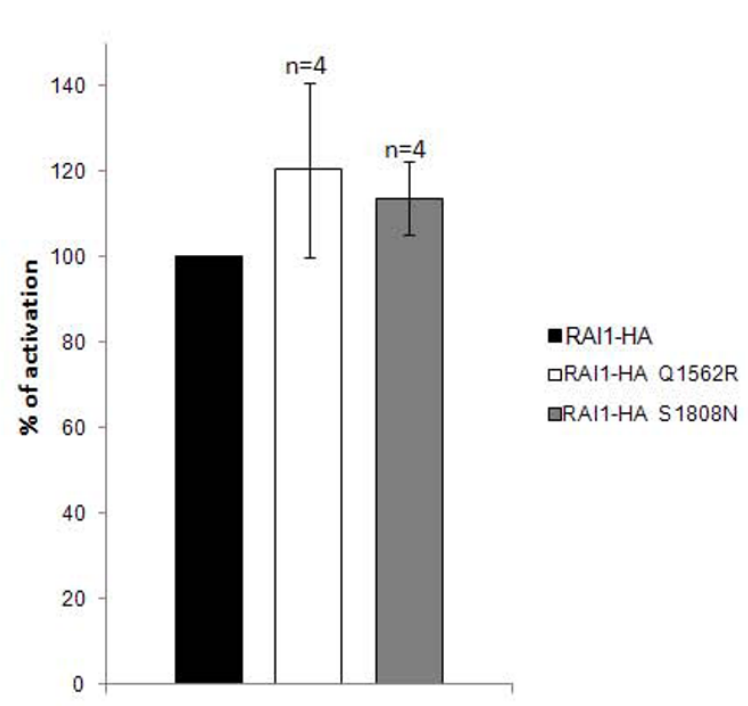

B)

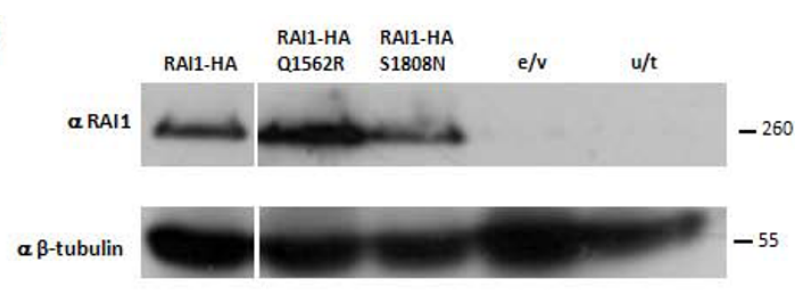

D)
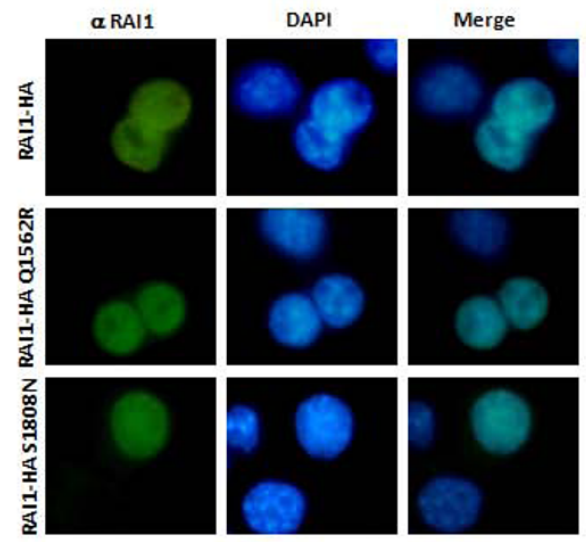

IF $\alpha$ RAI1

\begin{tabular}{lcc|c}
\hline \multicolumn{3}{c}{ If $\alpha$ RAI1 } \\
& \multicolumn{2}{c}{$\begin{array}{c}\text { Subcellular } \\
\text { localization }\end{array}$} & Total cell count \\
N & C & \\
\hline RAl1-HA & 198 & 2 & 200 \\
\hline RAI1-HA Q1562R & 195 & 5 & 200 \\
\hline RAI1-HA S1808N & 198 & 2 & 200 \\
\hline
\end{tabular}

Figure 4 Molecular evaluation of two point mutations associated with SMS. A) Schematic representation RAI1 Q1562R and RAI1 S1808N. In blue is represented the Poly-GIn domain, in yellow: Poly-Ser domains, in black: in silico described nuclear localization signals, in slanted line: the PHD domain. The coding sequence for HA epitope is represented in red. B) The molecular weight of mutated proteins was calculated in Neuro2 a cells by western blotting with anti RAl1 antibody. The obtained molecular weight is depicted and also the controls for the immunoreactivity are shown (e/v: extracts transfected only with the empty vector and $\mathrm{u} / \mathrm{t}$ represents untransfected cells control). C) The percentage of the reporter transcription activation is shown for RAl1-HA Q1562R (white) and RAl1-HA S1808N (grey) compared to RAl1-HA wild type protein (black). Values represent mean +/- SEM. D) Each plasmid was transfected in Neuro-2a cells and immunofluorescence was performed with anti RAl1 antibody and nuclei staining is shown with DAPI. The table represents subcellular localization of 200 cells immunodetected with anti RAI1 antibody. $\alpha=$ antibody against.

activity respectively, when compared with the wild type as $100 \%$. This is similar to what was found for the wild type RAI1-HA protein, indicating that the mutated polypeptides retained the transcription factor activity. We next evaluated the subcellular localization of the mutated proteins, and nuclear localization was found for both of them (figure 4D). All together these results indicate that RAI1 Q1562R and RAI1 S1808N mutations are not affecting the stability, transcription factor activity or subcellular localization of the protein.

\section{Discussion}

Alterations in the RAI1 gene have been associated with Smith-Magenis and Potocki-Lupski Syndromes whose clinical presentation includes autistic features, obsessivecompulsive behaviors, attention deficit, developmental delay, mental retardation, EEG abnormalities, sleep disturbances, self-injurious and maladaptive behaviors, among others [19-21]. In addition to this, RAI1 gene was associated with spinocerebellar ataxia (SCA2) [26], neuroleptic response in patients with schizophrenia [27], neurobehavioral traits manifested in SMS patients with RAI1 loss-of-function alleles [33-46] and non syndromic autism [28]. Despite its relationship with these important traits, there is lack of information about the molecular function of human RAI1.

Several heterozygous nucleotide variations in RAI1 gene have been found in SMS patients without 17p11.2 
deletions. These mutations include nonsense and missense mutations besides deletions of one or multiple nucleotides [15-18,43].

Within the RAI1 gene coding sequence there are several mononucleotide repeats. Intriguingly all five single base pair frameshift mutations found in the RAII gene associated with the SMS phenotype were in the C-tracts although the number of G-tracts in the RAI1 coding region is comparable with the $\mathrm{C}$-tracts [18]. Interestingly, in our laboratory a spontaneous deletion of a $\mathrm{C}$ in a four $\mathrm{C}$-tract at the position 2687 occurred, providing further evidence that polyC-tract may be a preferential target for frameshift mutations in RAI1.

Here we generated and studied the full-length cDNA of human wild type RAI1 and five mutated forms of the protein. Four of them previously associated with SMS. As deletions appear to be a very frequent event in the $R A I 1$ coding region, we also included in this study the spontaneously generated $2687 \mathrm{delC}$. In order to complement these studies, we have constructed two smaller proteins corresponding to the residues 1038-1906 and 1229-1906.

It was previously reported that mouse Rai1 has moderate transactivational activity in HeLa cells [29]. Here we confirmed those previous findings and showed that Rai1 has a stronger transactivation activity in Neuro-2a cells, the neuronal derived cell line. These results suggest specificity in the transcription machinery that RAI1 could be part of and further indicate the importance of its role in neuronal derived tissues, since $R A I 1$ is a dosage sensitive gene involved in neurobehavioral phenotypes.

Here we report that the wild type human RAI1 protein has transcription factor activity. Our studies of truncated proteins associated with $2687 \mathrm{delC}$ and 3103delC frameshifts plus R960X mutant, showed transcription factor activity significantly higher than the wild type protein for the resulting polypeptides. Moreover, the analysis of the two smaller proteins corresponding to the residues 1038-1906 and 1229-1906 showed no capability of activating transcription themselves. According to our results, the human RAI1 showed that the most important region of the protein for stimulating transcription is the $\mathrm{N}$-terminal half, until residue 1034 . From the residue 1038 to the end of RAI1 a fragment able to regulate the transactivational activity of the protein or the machinery associated may be present, since all truncated proteins showed a significant increase in transcription activity when compared to the full-length protein. In the $\mathrm{N}$-terminal region, corresponding approximately to the first half of the protein, there is a homology of $\sim 84 \%$ between human and murine RAI1. For the murine Rai1 protein, putative transactivation domains were mapped by fusion of different regions to
GAL4-BD [29]. The polypeptides containing residues 1-582 or encompassing residues 583 to 1142 have been shown to have transactivation activity while no transactivation activity was found in the region containing the remaining half; consistent with what is reported here for the human protein.

By bioinformatics analysis two putative bipartite nuclear localization signals (NLSs) were defined for RAI1 at positions 1113 and 1176 aa respectively [15]. Despite that we cannot discard the participation of the previously described NLS in the nuclear localization of the RAI1 protein, our results indicate that there is a nuclear localization signal that resides between 1229 aa to the end since the two smaller proteins 1038-1906 and 1229-1906 were able to localize in the nucleus; while the two N-terminal polypeptides were retained in the cytoplasm. These results suggest the presence of another fragment within the C-terminal half of RAI1 that modulates the nuclear localization of the protein. Accordingly, in vitro studies of the murine Rail protein indicated that it can be transported to the nucleus and that the nuclear localization signals reside between the 11341164 and 1203-1229 aa. Besides, on the C-terminal half of Rai1 there are other regions that are also able to transport the protein to the nucleus [29].

Taking these results together, we can define two clear domains in RAI1: an N-terminal half critical for its transactivational activity and a C-terminal half responsible for its nuclear transportation. In addition, to the Cterminus of both human and mouse RAI1, a zinc finger like plant homeo domain (PHD), which is also present in the trithorax family of chromatin remodeling transcriptional regulators was defined [16]. All these different domains are depicted in figure 5.

The truncated proteins generated by mutations 2687delC, 3103delC and R960X showed to be functional and moreover, they have an increased capability for activating the transcription when compared to the wild type protein. However, none of the resulting polypeptides were able to localize in the nucleus, suggesting that this inability (even retaining transcription factor activity) would be the main pathological way of action for these mutations.

Finally, there are spare cases of SMS patients with mutations in the RAI1 gene. We generated two independent mutations, RAI1 Q1562R and RAI1 S1808N. No abnormal molecular weight, subcellular localization or transcription factor activity were found for any of these mutants, suggesting that they may be implicated in the association with other proteins or some other functional role of RAI1 that is not known to date.

\section{Conclusion}

We were able to demonstrate that the human wild type protein has transcription factor activity, and is able to 


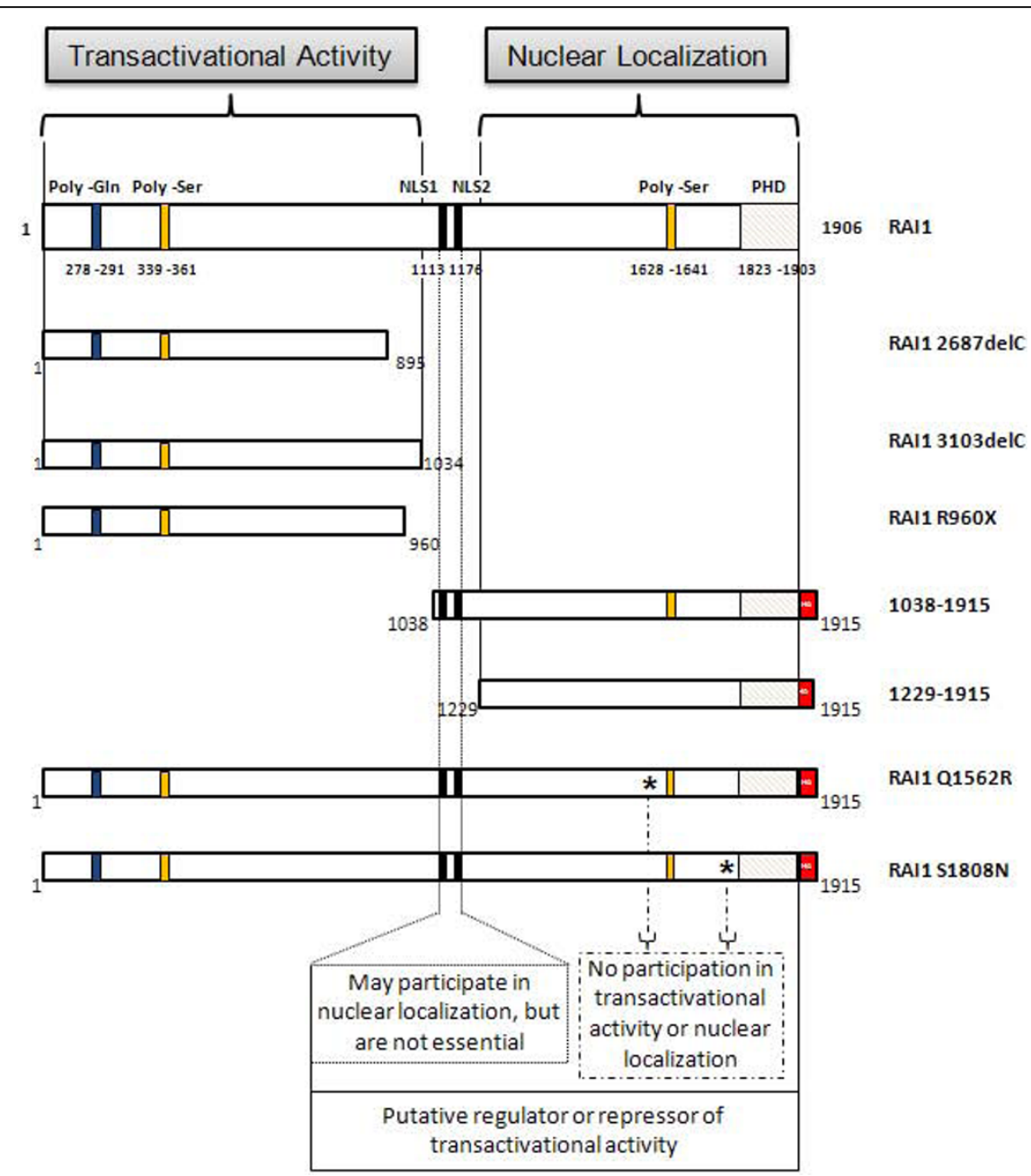

Figure 5 Summary of the results and definition of two domains in the structure of RAl1. By in silico analyses, several domains have been found for RAl1: a polyglutamine tract at the N-terminal of the protein (in blue), two polyserine domains (in yellow), a PHD domain at the C-terminal of RAl1 (in slanted lines) and two putative nuclear localization signals (in black). The schematic representation of all the mutants analyzed in this study is shown. An asterisk represents the missense mutations. Two defined domains are depicted.

localize to the nucleus. Moreover, we could define a transcription factor domain within the first 1034 aa and that the nuclear localization signals reside in the second half the protein. Altogether the analysis of the mutant proteins indicates that both halves are necessary for the correct subcellular localization and function of the protein, and that other molecular/functional role of RAI1 remains unknown.

\section{Methods}

\section{Plasmid Constructs}

The full-length clone of murine Rai1 was kindly provided by Dr. James Lupski, Department of Molecular \& Human Genetics, Baylor College of Medicine, Houston, Texas, USA. The sequence of influenza virus hemagglutinin epitope (HA) was added to the $3^{\prime}$ extreme to generate a tag by PCR using pCR3.1 Rai1 as template, with the primers Forward: GCCTCATCCTGAGAAGCAAC and Reverse: AAGTCTAGATTAAGCGTAATCTGGAACATCGTATGGGTACAACGGCAGCCTCTTA TGTTTG. The reverse primer contains the last 22 nucleotides of Rail cDNA without its stop codon, the coding sequence of hemagglutinin epitope, followed by a stop codon and an XbaI restriction site. The product of the reaction was purified and ligated into pGEM-T easy vector (Promega) and sequenced. In order to obtain the full-length Rai1-HA clone this PCR fragment was subcloned into the pCR3.1 Rai1 between the $A c c \mathrm{I}$ and $\mathrm{Xba \textrm {I }}$ sites.

As a first step to obtain the complete RAI1 cDNA a PCR product was generated by amplification of a human brain cDNA library with the following primers: Forward: GGCCTGGTAAATGTGGGCACCGGG and Reverse: 
AAGGCGGCCGCTTAAGCGTAATCTGGAACATCGTATGGGTACGGCAGCCTCTTATGTTTGGGAC. The reverse primer was designed to add the influenza virus hemagglutinin epitope tag (HA) and the NotI restriction site at the 3' extreme. Finally, the partial $5^{\prime}$ end cDNA RAI1 clone (KIAA1820, Kazusa DNA Research Institute, Japan) was ligated with the $\sim 1.5 \mathrm{~kb}$ fragment that contained the $3^{\prime}$ end of the cDNA with BamHI and NotI enzymes. The complete RAI1 cDNA clone was totally sequenced.

Three different point mutants were generated by sitedirected mutagenesis by PCR with the kit QuickChange Site-Directed Mutagenesis XL Kit (Stratagene) utilizing the following primers: for the mutation A4685G, Forward: GCGACGACGACGGCAGCAGGTGCTG and Reverse: CAGCACCTGCTGCCGTCGTCGTCGC; for the mutation G5423A, Forward: CAAACATGAGTGCAACAAGGAGGCTC and Reverse: GAGCCTCCT TGTTGCACTCATGTTTG, for the deletion 3103delC, Forward: CTGCACAGGGCCCCCCAGGGACAGATGGAA and Reverse: CTTCCATCTGTCCCTGGGGGG CCCTGTGCAG. The deletion $2687 \mathrm{delC}$ was a spontaneous deletion found during the sequencing. The cDNA for the truncated protein R960X was generated by PCR with the following primers, Forward: CTGACCGGT GGCTGGAGGAC and Reverse: TGGTGGAATCCC CTGGAGCTCCTACTCC. The product contains a stop codon instead of base 2878. This fragment was subcloned into full-length RAI1 cDNA with the enzyme SacI. All clones were verified by DNA sequencing.

Two C-terminal fragments of the RAI1 protein were generated using the following primers: for the fragment 1038-1915, Forward: GGGACAGATGGAAGGGGC TGG and for the fragment 1229-1915, Forward: GTCG GCCTTCATGGCGCCG. Both amplification reactions were performed with the same primer reverse used for generating the full-length clone, detailed above, which contains the HA tag and the NotI restriction site at the $3^{\prime}$ extreme. PCR products obtained were fully verified by DNA sequencing.

For expression analysis, the cDNAs of RAI1 wild type and mutant forms were subcloned in PALTER-MAX vector (Promega).

\section{Accession numbers}

For KIAA1820 [GenBank: AB058723], Mouse Rai1 [GenBank: NM_009021 and Swiss-Prot: Q61818]. For Human RAI1 [GenBank: NM_030665 and Swiss-Prot: Q7Z5J4].

\section{Cell Culture}

Neuro-2a and HeLa cells were grown in Dulbecco's Modified Eagle Medium supplemented with 10\% fetal bovine serum, penicillin (100 units $/ \mathrm{ml})$, streptomycin
$(100 \mu \mathrm{g} / \mathrm{ml})$ (Gibco by Invitrogen) at $37^{\circ} \mathrm{C}$ with $5 \% \mathrm{CO}_{2}$ until $95 \%$ confluence was attained.

\section{Immunofluorescence and Western blot analysis}

To study the expression of the proteins generated, Neuro-2a cells were transfected using Lipofectamine 2000 (Invitrogen), with the mouse plasmid pCR3.1 Rai1$H A$ and human constructs pALTER-MAX RAI1-HA wild type, RAI1-HA Q1562R, RAI1-HA S1808N, RAI1 R960X, RAI1-HA 2687delC, RAI1HA 3103delC, RAI1HA 1038-1915 and RAI1HA 1229-1915. All transfections were performed according to manufacturer's protocol.

For immunofluorescence, cells were fixed $36 \mathrm{~h}$ after transfection with $4 \%$ paraformaldehyde followed by permeabilization with $0.1 \%$ Triton X-100 in PBS. Subcellular localization of RAI1-HA wild type and mutant forms of the protein were detected using rabbit anti human RAI1 polyclonal antibody (1:200, ab58658 Abcam) whose epitope locates at the amino-terminal of RAI1. A secondary antibody conjugated to Alexa fluor 488 (1:500) was used. Cells were mounted in a medium with DAPI (Vector Laboratories).

For western blot analysis, total protein extracts were prepared $48 \mathrm{~h}$ after transfection. Cells were lysed in 100 $\mu \mathrm{l}$ of protein extraction and loading buffer ( $2 \%$ SDS, 2 M Urea, 10\% Glycerol, $10 \mathrm{mM}$ Tris pH 6.8, 0.002\% Bromophenol Blue and $10 \mathrm{mM}$ DTT) plus 1:200 protease inhibitor cocktail (SIGMA). The samples were homogenized passing 20 times through a syringe and warmed up to $95^{\circ} \mathrm{C}$ for 5 minutes. $25 \mu$ of each cell lysate was loaded onto 10\% SDS-polyacrylamide gels with Tris/glycine running buffer and transferred to a $0.2 \mu \mathrm{m}$ polyvinylidene fluoride (PVDF, Bio-Rad) membrane. Immunodetection was performed using rabbit anti human RAI1 polyclonal antibody (1:1000, Abcam) and rabbit anti $\beta$-tubulin (1:1000, sc-9104 Santa Cruz). Results were visualized by chemiluminiscence.

The detection of murine Rai1-HA and proteins 10381915 and 1229-1915 was done with anti HA high affinity antibody (1:5000 for Western blot and 1:1000 for immunofluorescence clone 3F10, Roche).

\section{Reporter gene assays}

Transient transfections in Neuro-2a cells were performed in $35 \mathrm{~mm}$ plates. The amounts of plasmid DNA used were according to manufacturer's protocol. GAL4$\mathrm{BD}$ fusions of mouse and human RAI1 wild type and all of its mutant forms were co-transfected with the luciferase reporter plasmid pFR-Luc (Stratagene) and the $\beta$-Galactosidase expression plasmid pSV- $\beta$-Galactosidase (for normalization of the transfection efficiency). Forty eight hours post-transfection, cells were lysed and luciferase assays were performed with Luciferase Assay Kit 
(Stratagene), according to manufacturer's instructions. The Relative Lights Units (RLUs) were measured in duplicate in a Syrius Luminometer (Berthold Detection Systems).

$\beta$-Galactosidase activities were measured with $810 \mu \mathrm{l}$ of $\beta$-Galactosidase buffer $\left(60 \mathrm{mM} \mathrm{Na}_{2} \mathrm{HPO}_{4}, 40 \mathrm{mM}\right.$ $\mathrm{NaH}_{2} \mathrm{PO}_{4}, 10 \mathrm{mM} \mathrm{KCl}, 1 \mathrm{mM} \mathrm{MgCl} 2$ and $50 \mathrm{mM}$ $\beta$-mercaptoethanol) for $50 \mu \mathrm{l}$ of cell lysates plus $160 \mu \mathrm{l}$ ONPG reagent $\left(60 \mathrm{mM} \mathrm{Na}_{2} \mathrm{HPO}_{4}, 40 \mathrm{mM} \mathrm{NaH} \mathrm{mO}_{4}\right.$ and $4 \mathrm{mg} / \mathrm{ml}$ ONPG (o-Nitrophenyl- $\beta$-D-Galactopyranoside). Incubations were performed at $30^{\circ} \mathrm{C}$, reactions were stopped by adding $250 \mu \mathrm{l}$ of $\mathrm{Na}_{2} \mathrm{CO}_{3} 1 \mathrm{M}$. The absorbance was read at $420 \mathrm{~nm}$. Each cell assay was carried out in duplicate.

\section{Acknowledgements}

We thank Ana Lorenzo and Irene Perez for administrative support and English editing of the manuscript. This work was supported by FONDECYT [grant 1061067 (KW), 1051079 (JIY)], FIC [R03 TW07536 (KW)]. The Centro de Estudios Cientificos (CECS) is funded by the Chilean Government through the Millennium Science Initiative and the Centers of Excellence Base Financing Program of Conicyt. CECS is also supported by a group of private companies which at present include Antofagasta Minerals, Arauco, Empresas CMPC, Indura, Naviera Ultragas and Telefónica del Sur.

\section{Author details}

'John P. Hussman Institute for Human Genomics, Miller School of Medicine, University of Miami, Miami, Florida, USA. ${ }^{2}$ Centro de Estudios Científicos, CECS, Valdivia, Chile. ${ }^{3}$ Universidad Austral de Chile, Valdivia, Chile. ${ }^{4}$ Centro de Ingeniería de la Innovación (CIN), CECS, Valdivia, Chile.

\section{Authors' contributions}

PCM, CAE, CPC, LC, JM and PK carried out the experiments. PCM, CAE, JIY and KW participated in the design of the study. PCM and KW conceived the work and drafted the manuscript. KW supervised and coordinated the study. All authors read and approved the final manuscript.

Received: 18 March 2010 Accepted: 25 August 2010

Published: 25 August 2010

\section{References}

1. lafrate AJ, Feuk L, Rivera MN, Listewnik ML, Donahoe PK, Qi Y, Scherer SW, Lee C: Detection of large-scale variation in the human genome. Nat Genet 2004, 36:949.

2. Redon R, Ishikawa S, Fitch KR, Feuk L, Perry GH, Andrews TD, Fiegler H, Shapero MH, Carson AR, Chen W, Cho EK, Dallaire S, Freeman JL, González JR, Gratacòs M, Huang J, Kalaitzopoulos D, Komura D, MacDonald JR, Marshall CR, Mei R, Montgomery L, Nishimura K, Okamura K, Shen F, Somerville MJ, Tchinda J, Valsesia A, Woodwark C, Yang F, et al: Global variation in copy number in the human genome. Nature 2006, 444:444.

3. Beckmann JS, Estivill X, Antonarakis SE: Copy number variants and genetic traits: Closer to the resolution of phenotypic to genotypic variability. Nat Rev Genet 2007, 8:639.

4. Korn JM, Kuruvilla FG, McCarroll SA, Wysoker A, Nemesh J, Cawley S, Hubbell E, Veitch J, Collins PJ, Darvishi K, Lee C, Nizzari MM, Gabriel SB, Purcell S, Daly MJ, Altshuler D: Integrated genotype calling and association analysis of SNPs, common copy number polymorphisms and rare CNVs. Nat Genet 2008, 40:1253.

5. McCarroll SA, Kuruvilla FG, Korn JM, Cawley S, Nemesh J, Wysoker A, Shapero MH, de Bakker PI, Maller JB, Kirby A, Elliott AL, Parkin M, Hubbell E, Webster T, Mei R, Veitch J, Collins PJ, Handsaker R, Lincoln S, Nizzari M, Blume J, Jones KW, Rava R, Daly MJ, Gabriel SB, Altshuler D: Integrated detection and population-genetic analysis of SNPs and copy number variation. Nat Genet 2008, 40:1166.
6. Conrad DF, Pinto D, Redon R, Feuk L, Gokcumen O, Zhang Y, Aerts J, Andrews TD, Barnes C, Campbell P, Fitzgerald T, Hu M, Ihm CH, Kristiansson K, Macarthur DG, Macdonald JR, Onyiah I, Pang AW, Robson S, Stirrups K, Valsesia A, Walter K, Wei J, Wellcome Trust Case Control Consortium, Tyler-Smith C, Carter NP, Lee C, Scherer SW, Hurles ME: Origins and functional impact of copy number variation in the human genome. Nature 2010, 1:464(7289):704, [Epub 2009 Oct 7].

7. Lupski JR: Genomic disorders: Structural features of the genome can lead to DNA rearrangements and human disease traits. Trends Genet 1998, 14:417.

8. Greenberg F, Guzzetta V, Montes de Oca-Luna R, Magenis RE, Smith AC, Richter SF, Kondo I, Dobyns WB, Patel PI, Lupski JR: Molecular analysis of the Smith-Magenis syndrome: A possible contiguous-gene syndrome associated with del(17)(p11.2). Am J Hum Genet 1991, 49:1207.

9. Juyal RC, Figuera LE, Hauge X, Elsea SH, Lupski JR, Greenberg F, Baldini A, Patel PI: Molecular analyses of 17p11.2 deletions in 62 Smith-Magenis syndrome patients. Am J Hum Genet 1996, 58:998.

10. Chen KS, Manian P, Koeuth T, Potocki L, Zhao Q, Chinault AC, Lee CC, Lupski JR: Homologous recombination of a flanking repeat gene cluster is a mechanism for a common contiguous gene deletion syndrome. Nat Genet 1997, 17:154

11. Vlangos CN, Yim DK, Elsea SH: Refinement of the Smith-Magenis syndrome critical region to approximately $950 \mathrm{~kb}$ and assessment of 17p11.2 deletions. Are all deletions created equally? Mol Genet Metab 2003, 79:134.

12. Lucas RE, Vlangos CN, Das P, Patel Pl, Elsea SH: Genomic organisation of the approximately $1.5 \mathrm{Mb}$ Smith-Magenis syndrome critical interval: Transcription map, genomic contig, and candidate gene analysis. Eur J Hum Genet 2001, 9:892.

13. Bi W, Yan J, Stankiewicz P, Park SS, Walz K, Boerkoel CF, Potocki L, Shaffer LG, Devriendt K, Nowaczyk MJ, Inoue K, Lupski JR: Genes in a refined Smith-Magenis syndrome critical deletion interval on chromosome 17p11.2 and the syntenic region of the mouse. Genome Res 2002, 12:713.

14. Zody MC, Garber M, Adams DJ, Sharpe T, Harrow J, Lupski JR, Nicholson C, Searle SM, Wilming L, Young SK, Abouelleil A, Allen NR, Bi W, Bloom T, Borowsky ML, Bugalter BE, Butler J, Chang JL, Chen CK, Cook A, Corum B, Cuomo CA, de Jong PJ, DeCaprio D, Dewar K, FitzGerald M, Gilbert J, Gibson R, Gnerre S, Goldstein S: DNA sequence of human chromosome 17 and analysis of rearrangement in the human lineage. Nature 2006, 440:1045.

15. Slager RE, Newton TL, Vlangos CN, Finucane B, Elsea SH: Mutations in RAl1 associated with Smith-Magenis syndrome. Nat Genet 2003, 33:466.

16. Bi W, Saifi GM, Shaw CJ, Walz K, Fonseca P, Wilson M, Potocki L, Lupski JR: Mutations of RAl1, a PHD-containing protein, in nondeletion patients with Smith-Magenis syndrome. Hum Genet 2004, 115:515.

17. Girirajan S, Elsas $L$, Devriendt K, Elsea SH: RAl1 variations in SmithMagenis syndrome patients without 17p11.2 deletions. J Med Genet 2005, 42:820.

18. Bi W, Saifi GM, Girirajan S, Shi X, Szomju B, Firth H, Magenis RE, Potocki L, Elsea SH, Lupski JR: RAl1 point mutations, CAG repeat variation, and SNP analysis in non-deletion Smith-Magenis syndrome. Am J Med Genet A 2006, 140:2454.

19. Walz K, Paylor R, Yan J, Bi W, Lupski JR: Rai1 duplication causes physical and behavioral phenotypes in a mouse model of dup(17)(p11.2p11.2). J Clin Invest 2006, 116:3035.

20. Potocki L, Bi W, Treadwell-Deering D, Carvalho CM, Eifert A, Friedman EM, Glaze D, Krull K, Lee JA, Lewis RA, Mendoza-Londono R, Robbins-Furman P, Shaw C, Shi X, Weissenberger G, Withers M, Yatsenko SA, Zackai EH, Stankiewicz P, Lupski JR: Characterization of Potocki-Lupski syndrome (dup(17)(p11.2p11.2)) and delineation of a dosage-sensitive critical interval that can convey an autism phenotype. Am J Hum Genet 2007, 80:633.

21. Zhang F, Potocki L, Sampson JB, Liu P, Sanchez-Valle A, Robbins-Furman P, Navarro AD, Wheeler PG, Spence JE, Brasington CK, Withers MA, Lupski JR: Identification of uncommon recurrent Potocki-Lupski syndromeassociated duplications and the distribution of rearrangement types and mechanisms in PTLS. Am J Hum Genet 2010, 86:462.

22. Potocki L, Chen KS, Park SS, Osterholm DE, Withers MA, Kimonis V, Summers AM, Meschino WS, Anyane-Yeboa K, Kashork CD, Shaffer LG, Lupski JR: Molecular mechanism for duplication 17p11.2- the 
homologous recombination reciprocal of the Smith-Magenis microdeletion. Nat Genet 2000, 24:84.

23. Treadwell-Deering DE, Powell MP, Potocki L: Cognitive and behavioral characterization of the Potocki-Lupski syndrome (duplication 17p11.2). J Dev Behav Pediatr 2010, 31:137.

24. Toulouse A, Rochefort D, Roussel J, Joober R, Rouleau GA: Molecular cloning and characterization of human RAl1, a gene associated with schizophrenia. Genomics 2003, 82:162.

25. Imai Y, Suzuki Y, Matsui T, Tohyama M, Wanaka A, Takagi T: Cloning of a retinoic acid-induced gene, GT1, in the embryonal carcinoma cell line P19: Neuron-specific expression in the mouse brain. Brain Res Mol Brain Res 1995, 31:1.

26. Hayes S, Turecki G, Brisebois K, Lopes-Cendes I, Gaspar C, Riess O, Ranum LP, Pulst SM, Rouleau GA: CAG repeat length in RA/1 is associated with age at onset variability in spinocerebellar ataxia type 2 (SCA2). Hum Mol Genet 2000, 9:1753.

27. Joober R, Benkelfat $C$, Toulouse A, Lafrenière RG, Lal S, Ajroud S, Turecki $G$, Bloom D, Labelle A, Lalonde P, Alda M, Morgan K, Palmour R, Rouleau GA: Analysis of 14 CAG repeat-containing genes in schizophrenia. Am J Med Genet 1999, 88:694

28. van der Zwaag B, Franke L, Poot M, Hochstenbach R, Spierenburg HA, Vorstman JA, van Daalen E, de Jonge MV, Verbeek NE, Brilstra EH, van't Slot R, Ophoff RA, van Es MA, Blauw HM, Veldink JH, Buizer-Voskamp JE, Beemer FA, van den Berg LH, Wijmenga C, van Amstel HK, van Engeland $H$, Burbach JP, Staal WG: Gene-network analysis identifies susceptibility genes related to glycobiology in autism. PLoS One 2009, 4:e5324.

29. Bi W, Ohyama T, Nakamura H, Yan J, Visvanathan J, Justice MJ, Lupski JR: Inactivation of Rai1 in mice recapitulates phenotypes observed in chromosome engineered mouse models for Smith-Magenis syndrome. Hum Mol Genet 2005, 14:983.

30. Carmona-Mora P, Molina J, Encina CA, Walz K: Mouse models of genomic syndromes as tools for understanding the basis of complex traits: An example with the Smith-Magenis and the Potocki-Lupski syndromes. Curr Genomics 2009, 10:259.

31. Julenius K, Molgaard A, Gupta R, Brunak S: Prediction, conservation analysis, and structural characterization of mammalian mucin-type O-glycosylation sites. Glycobiology 2005, 15:153.

32. Silver PA, Keegan LP, Ptashne M: Amino terminus of the yeast GAL4 gene product is sufficient for nuclear localization. Proc Natl Acad Sci USA 1984, 81:5951.

33. Colley AF, Leversha MA, Voullaire LE, Rogers JG: Five cases demonstrating the distinctive behavioural features of chromosome deletion 17(p11.2 p11.2) (Smith-Magenis syndrome). J Pediatr Child Health 1990, 26:17.

34. Finucane BM, Konar D, Haas-Givler B, Kurtz MB, Scott Cl Jr: The spasmodic upper-body squeeze: A characteristic behavior in Smith-Magenis syndrome. Dev Med Child Neurol 1994, 36:78.

35. Greenberg F, Lewis RA, Potocki L, Glaze D, Parke J, Killian J, Murphy MA, Williamson D, Brown F, Dutton R, McCluggage C, Friedman E, Sulek M, Lupski JR: Multi-disciplinary clinical study of Smith-Magenis syndrome (deletion 17p11.2). Am J Med Genet 1996, 62:247.

36. Clarke DJ, Boer H: Problem behaviors associated with deletion PraderWilli, Smith-Magenis, and cri du chat syndromes. Am J Ment Retard 1998, 103:264.

37. Dykens EM, Smith AC: Distinctiveness and correlates of maladaptive behaviour in children and adolescents with Smith-Magenis syndrome. J Intellect Disabil Res 1998, 42:481.

38. Smith AC, Dykens E, Greenberg F: Behavioral phenotype of SmithMagenis syndrome (del 17p11.2). Am J Med Genet 1998, 81:179.

39. Smith AC, Dykens E, Greenberg F: Sleep disturbance in Smith-Magenis syndrome (del 17 p11.2). Am J Med Genet 1998, 81:186.

40. Potocki L, Glaze D, Tan DX, Park SS, Kashork CD, Shaffer LG, Reiter RJ, Lupski JR: Circadian rhythm abnormalities of melatonin in Smith-Magenis syndrome. J Med Genet 2000, 37:428.

41. De Leersnyder H, De Blois MC, Claustrat B, Romana S, Albrecht U, Von Kleist-Retzow JC, Delobel B, Viot G, Lyonnet S, Vekemans M, Munnich A: Inversion of the circadian rhythm of melatonin in the Smith-Magenis syndrome. J Pediatr 2001, 139:111.

42. Potocki L, Shaw CJ, Stankiewicz P, Lupski JR: Variability in clinical phenotype despite common chromosomal deletion in Smith-Magenis syndrome [del(17)(p11.2p11.2)]. Genet Med 2003, 5:430.
43. Girirajan $S$, Vlangos CN, Szomju BB, Edelman E, Trevors CD, Dupuis L, Nezarati M, Bunyan DJ, Elsea SH: Genotype-phenotype correlation in Smith-Magenis syndrome: Evidence that multiple genes in 17p11.2 contribute to the clinical spectrum. Genet Med 2006, 8:417.

44. Goldman AM, Potocki L, Walz K, Lynch JK, Glaze DG, Lupski JR, Noebels JL: Epilepsy and chromosomal rearrangements in Smith-Magenis syndrome [del(17)(p11.2p11.2)]. J Child Neurol 2006, 21:93.

45. Madduri N, Peters SU, Voigt RG, Llorente AM, Lupski JR, Potocki L: Cognitive and adaptive behavior profiles in Smith-Magenis syndrome. J Dev Behav Pediatr 2006, 27:188.

46. Edelman EA, Girirajan S, Finucane B, Patel PI, Lupski JR, Smith AC, Elsea SH: Gender, genotype, and phenotype differences in Smith-Magenis syndrome: A meta-analysis of 105 cases. Clin Genet 2007, 71:540.

doi:10.1186/1471-2199-11-63

Cite this article as: Carmona-Mora et al:: Functional and cellular characterization of human Retinoic Acid Induced 1 (RAI1) mutations associated with Smith-Magenis Syndrome. BMC Molecular Biology 2010 11:63.

\section{Submit your next manuscript to BioMed Central and take full advantage of:}

- Convenient online submission

- Thorough peer review

- No space constraints or color figure charges

- Immediate publication on acceptance

- Inclusion in PubMed, CAS, Scopus and Google Scholar

- Research which is freely available for redistribution 